\title{
Hannah Arendt e o resgate do conceito de totalitarismo
}

\author{
Márcio Roberto Malcher Furtado*
}

Resumo: Tendo em vista os inumeráveis empregos do conceito totalitário arendtiano no senso comum, o presente artigo tem por finalidade resgatar tal conceito para que o mesmo seja aplicado acertadamente no contexto sociopolítico atual. Portanto, o conceito foi abordado via a obra Origens do Totalitarismo (1951), na qual o fenômeno do totalitarismo foi esquadrinhado e meticulosamente analisado pela teórica política Hannah Arendt. A pensadora procurou compreender como foi possível ocorrer o fenômeno totalitário, assim como quais foram os elementos que contribuíram para o seu surgimento. Muito embora o conceito arendtiano seja mais bem aplicável dentro de seu tempo e espaço, pretende-se resgatar os princípios básicos norteadores delineados pela escritora, a fim de melhor compreender o desenvolvimento da questão na contemporaneidade.

Palavras-chave: Totalitarismo, Terror, Nazismo, Comunismo, Liberdade.

\begin{abstract}
In view of the numerous employments common sense gives to Arendt's concept of totalitarianism, this article aims to retrieve this concept so that it can be accurately applied in the current socio-political context. Therefore, the concept was approached via the Origins of Totalitarianism (1951), where the phenomenon of totalitarianism was scrutinized and meticulously analyzed by the political theorist Hannah Arendt. The philosopher sought to understand how the totalitarian phenomenon became possible, as well as what were the elements that contributed to its emergence. Although the Arendtian concept is best applicable within its time and space, this article intends to recapture the basic guiding principles outlined by the writer in order to better understand the development of the issue in the contemporary world.
\end{abstract}

Keywords: Totalitarianism, Terror, Nazism, Communism, Freedom.

\footnotetext{
* Bacharel em Teologia pela Universidade Presbiteriana Mackenzie - UPM (2010). Experiência na área de Teologia, com ênfase em sociologia da religião, filosofia e psicologia. Graduando em Psicologia na Universidade São Judas Tadeu - USJT. Pós-graduando em Filosofia e Pensamento Político Contemporâneos na UNIFAI.
} 


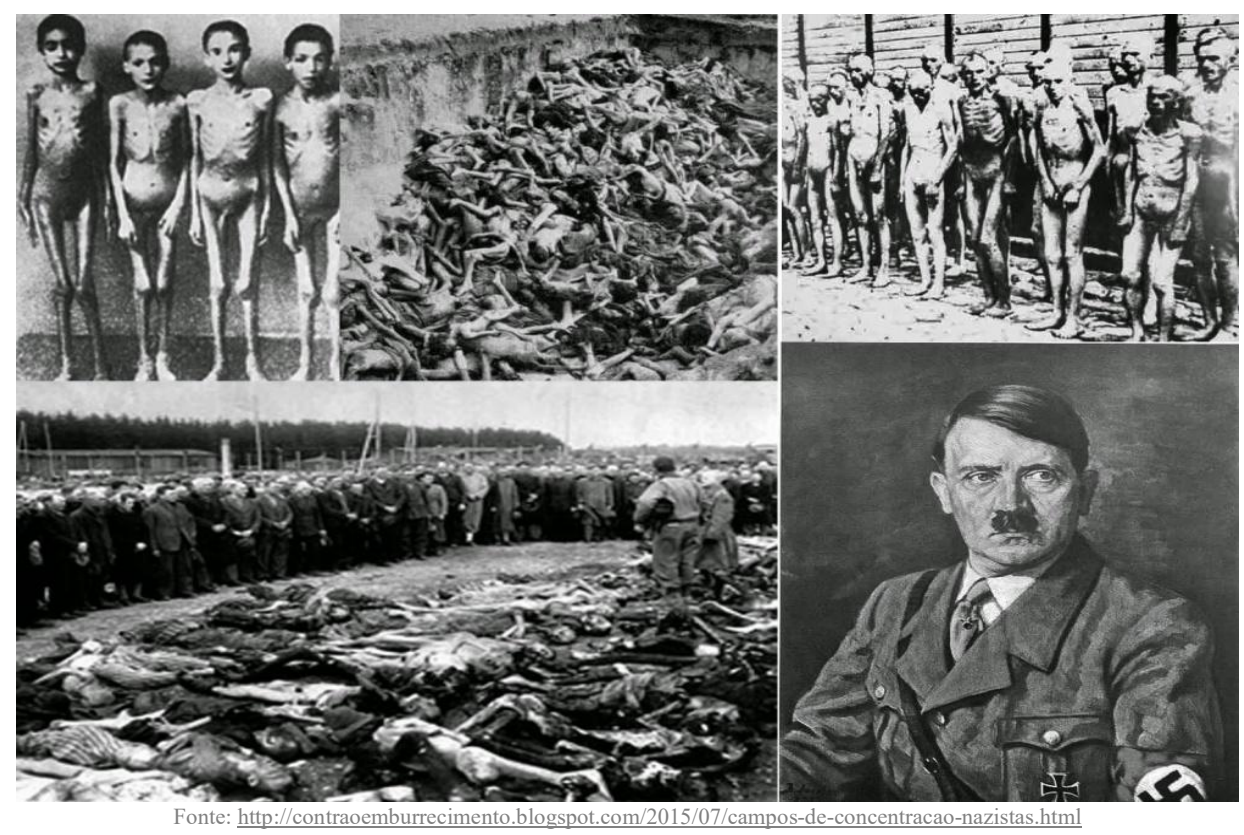

\section{Introdução}

$\mathrm{Na}$ atualidade, com o surgimento de líderes com características autoritárias e antidemocráticas, tem ocorrido uma movimentação intrigante, a ponto de os meios de comunicação, com pensadores e escritores, terem posto tais indivíduos nas fileiras de líderes totalitários ${ }^{1}$.

Um dos exemplos mais destacados ocorre nos EUA, pois desde que Donald Trump ascendeu ao poder, os leitores estadunidenses têm apresentado renovado interesse por livros com teor totalitário, acarretando um considerável aumento nas vendas de tais obras. Dentre elas destacam-se: o clássico “1984” de George Orwell (1949); It Can’t Happen Here, de Sinclair Lewis (1935), que retrata a eleição de um presidente autoritário nos Estados Unidos; Admirável novo mundo, de Aldous Huxley (1932); O Conto da Aia, premiado livro da escritora canadense Margaret Atwood (1985), e a obra de não-ficção Origens do totalitarismo, de Hannah Arendt $(1951)^{2}$.

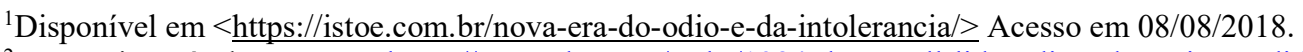

Disponível $\quad$ em<https://www.dw.com/pt-br/1984-de-orwell-lidera-lista-de-mais-vendidos-nos-eua/a37268181>A Deutsche Welle (DW) é uma empresa de comunicação internacional da Alemanha que produz jornalismo independente em 30 idiomas. Desde 2013, é comandada pelo diretor geral Peter Limbourg. Cerca de 3 mil jornalistas - contratados ou freelancers - provenientes de 60 países trabalham nas sedes da DW em Bonn e Berlim.Acesso em 23/07/2018.
} 
Sendo assim, a conceituação do fenômeno se faz necessária para que se tenha sobriedade na análise de eventos de violência no século presente, podendo ou não ser classificados como fenômenos totalitários.

No entanto, apesar de ser imprescindível o resgate e compreensão dos fatos históricos para a compreensão da contemporaneidade, é mister lembrar que, embora as observações de Hannah Arendt possam trazer luz aos acontecimentos presentes, não se pode perder de vista que sua análise se concentra sobre os acontecimentos histórico-políticos do período em que viveu. Portanto, seu arcabouço teórico não terá todas as soluções frente aos problemas atuais.

Por fim, o artigo não propõe analisar a violência no século XXI, mas sim resgatar e apresentar o conceito arendtiano de totalitarismo para que se tenham ferramentas para uma análise coerente e fiel das supostas atitudes totalitárias presentes neste século.

\section{Hannah Arendt e a natureza totalitária}

Estudar um pensador supõe-se esquadrinhá-lo e classificá-lo. Qual sua ocupação no campo da ciência, metodologia, viés político? No entanto, Hannah Arendt (1906-1975) extravasa tal classificação moderna. Uns vão denominá-la filósofa, outros preferem cientista política, ou até mesmo a junção destes: filósofa política. Alguns a classificam na vertente política esquerdista ${ }^{3}$, e tantos outros de direita $^{4}$. Uns a consideram uma liberal que desejava mudanças, outros, uma conservadora que desejava a estabilidade ${ }^{5}$. Comentadores enfatizam aspectos sócio-históricos de sua produção, enquanto outros destacam a qualidade literária e poética. É difícil dizer o que ela era. Todavia, não há melhor pessoa para dizer “o que se é” do que o próprio ser sobre quem se especula.

Em outubro de 1964, em uma entrevista ${ }^{6}$, o jornalista Günter Gaus afirmou que Arendt se ocupa da filosofia, portanto é filósofa, ao que a pensadora retorquiu:

Infelizmente tenho de protestar. Não pertenço ao círculo de filósofos. Minha profissão, se é que pode chamar assim, é a teoria política. [...]Eu me despedi da

\footnotetext{
${ }^{3}$ Quem identifica Hannah Arendt com a esquerda é, por exemplo, Gerhard Scholem em carta publicada em The Jew as Pariah, p.241. Tal obra, publicada postumamente em 1978, é uma coletânea de textos sobre temas judaicos, escritos entre 1942 e 1966, e focados em assuntos eminentemente políticos como sionismo, o Estado de Israel ou a paz com os árabes.

${ }^{4}$ Para os elementos de direita e esquerda em Hannah Arendt vide CANOVAN, Margaret. The Political Thought of Hannah Arendt. New York-London, Ed. Harvert-HJB, 1974.

${ }^{5}$ Em 1972, quando the indagaram se era liberal ou conservadora, respondeu: "Não sei [...] Você sabe que a esquerda acha que sou conservadora, e os conservadores às vezes acham que sou de esquerda, ou dissidente, ou sabe-se lá o quê. E confesso que não dou a menor importância. Não acho que o verdadeiro problema deste século ficará mais claro com esse tipo de assunto" (ARENDT, 2008, p.20).

6 "O que resta? Resta a língua": uma conversa com Günter Gaus. In ARENDT, Hannah. Compreender: formação, exílio e totalitarismo. São Paulo: Companhia das Letras; Belo Horizonte: Editora UFMG, 2008.
} 
filosofia de uma vez por todas. Como você sabe, estudei filosofia, mas isso não significa que continuei com ela (ARENDT, 2008, p.31).

Apesar da clareza na resposta, o jornalista insistiu, perguntando a diferença entre filosofia política e teoria política. Assim Arendt lhe respondeu:

\begin{abstract}
A expressão filosofia política, que costumo evitar, está sobrecarregada pela tradição. Quando falo sobre essas coisas, academicamente ou não, sempre digo que existe uma tensão vital entre filosofia e política. Isto é, entre o homem como ser pensante e o homem como ser atuante há uma tensão que não existe na filosofia natural, por exemplo. Como todo mundo, o filósofo pode ser objetivo em relação à natureza e, quando diz o que pensa sobre ela, ele fala em nome de toda a humanidade. Mas ele não pode ser objetivo ou neutro em relação à política. Não desde Platão! [...] Quero olhar a política, por assim dizer, com os olhos não toldados pela filosofia (ARENDT, 2008, p.32).
\end{abstract}

Ao contrário do filósofo, o pensador político deve envolver-se, ou seja, não há espaço para a neutralidade. (Re)pensar a política resulta participação. Portanto, partindo desses argumentos, entende-se o porquê de Arendt recusar a denominação de filósofa. Parece que tal termo a coloca no mesmo lugar daqueles que ficam a pensar sentados em suas belas escrivaninhas, apartados do mundo real. Agir assim excluiria toda a experiência totalitária que ela viveu na própria pele (perseguição, prisão e fuga).

Arendt vem de uma formação puramente acadêmica. Os anos universitários coadunaram com a relativa estabilidade da República de Weimar. E foi justamente nesse meio que ela presenciou os acontecimentos nazistas passarem do genericamente político para o pessoal. O maior amargor provinha da delação de seus próprios amigos. Ageichschaltung ${ }^{7}$, até então relativamente voluntária, segundo Arendt, era regra entre os intelectuais, o que não ocorria em outros círculos sociais. A pensadora relata: "nunca esqueci isso. Saí da Alemanha dominada pela ideia, claro que um pouco exagerada: Nunca mais! Nunca mais vou me envolver em nenhum tipo de atividade intelectual" (ARENDT, 2008, p.41). Foi justamente esta crise que fez Arendt abandonar a linha eminentemente intelectual de seu trabalho e partir para algo de natureza prática.

O choque de 1933 culminou com a saída de Arendt em direção a Paris. Lá, procurou trabalho prático e passou a atuar numa instituição que amparava jovens, levando-os da Alemanha para a Palestina.

\footnotetext{
${ }^{7}$ Geichschaltung, ou coordenação política, refere-se ao processo generalizado, no início da era nazista, de contribuir com a nova ordem política a fim de assegurar status social ou adquirir emprego. Além do mais, designa a política nazista de persuadir organizações tradicionais (grupos de jovens e todas as espécies de clubes e associações) em organizações minuciosamente nazistas (ARENDT, 2008, p.40).
} 
As crianças recebiam formação e reciclagem profissional. Algumas vezes também trouxe escondidas crianças polonesas. Era um trabalho social, um trabalho educacional regular. Havia grandes acampamentos na área rural onde as crianças eram preparadas para a palestina, onde tinham aulas, onde aprendiam a plantar, onde principalmente tinham de ganhar peso. Tínhamos de vesti-las da cabeça aos pés. Tínhamos de cozinhar para elas. E acima de tudo tínhamos de conseguir documentos para elas, tínhamos de combinar com os pais - e antes de qualquer outra coisa tínhamos de conseguir dinheiro para elas. Essa também, em larga medida, era minha tarefa. Trabalhava junto com mulheres francesas. É mais ou menos isso o que fazíamos (ARENDT, 2008, p.40).

Conclui-se, pelo exposto, que a recusa do título de filósofa não é gratuita, pois, para Hannah Arendt, seu trabalho não se deve limitar à contemplação e descrição do mundo, todavia, antes de mais nada, deve-se transformá-lo. Para ela é impossível pensar a política sem ação, ou seja, o pensamento político é intrinsecamente participativo.

Apesar das controvérsias sobre sua atuação, fato incontestável é que sua vida foi talhada pela atração irresistível de compreender. Tal atividade mental colaborou com novos conceitos e modificou antigas categorias do pensamento político clássico. Sua atividade de compreender lhe assegurou certa harmonização com o mundo em que habitava.

Compreender não significa negar nos fatos o chocante, eliminar deles o inaudito, ou, ao explicar fenômenos, utilizar-se de analogias e generalidades que diminuam o impacto da realidade e o choque da experiência. Significa, antes de mais nada, examinar e suportar conscientemente o fardo que nosso século colocou sobre nós sem negar sua existência, nem vergar humildemente ao seu peso. Compreender significa, em suma, encarar a realidade sem preconceitos e com atenção, e resistir a ela - qualquer que seja (ARENDT, 1989, p.12).

Boa parte dos pensadores se limita à produção de ideias e conceitos teóricos apartados da práxis, o que não ocorre com Arendt. Ademais, poucos pensadores possuem uma biografia tão vasta, atribulada e ativa. A produção intelectual arendtiana está arraigada em sua biografia, e não há como compreender seu pensamento desprezando sua vida vivida. A simbiose entre produção conceitual e vida é indissociável a tal ponto de não se saber qual destes fatores mais influenciou sua cosmovisão.

Neste sentido, pode-se conferir a opinião de Adeodato:

Deve-se ter presente, contudo, que o conflito entre participação e contemplação desempenhou papel importante na obra de Hannah Arendt e em seus progressivos desdobramentos entre filosofia "pura" e política; talvez a evolução do pensamento de autores de biografia menos conturbada não apresente uma relação tão direta entre teoria e as experiências de vida. No caso de Hannah Arendt, os dados biográficos adquirem uma relevância particular e são muitos úteis à compreensão de sua obra (ADEODATO, 1989, p.83). 
Nos anos 1920, ocorreram dois acontecimentos dicotômicos que acarretariam forte influência na evolução do pensamento e personalidade de Hannah Arendt. O primeiro foi ser discente de dois ilustres pensadores na vanguarda da filosofia existencialista: Martin Heidegger e Karl Jaspers ${ }^{8}$.

Com Heidegger, Hannah Arendt aprendeu que o pensamento deve ser apaixonado, envolver-se intimamente e tomar partido quando se dirige a um objeto, de modo em muito semelhante à abordagem poética. De Jaspers, nas palavras da própria Arendt seu verdadeiro mestre, com quem manteve amizade até o fim da vida, aprendeu o exemplo de uma vida firme e coerente e a convicção de que o filósofo precisa estar comprometido com o bem-estar da comunidade e, por extensão, de toda humanidade. De Husserl, via Heidegger, Hannah Arendt herda o método fenomenológico, embora utilize à sua maneira (ADEODATO, 1989, p.84).

Estas duas personagens acompanhariam Arendt ao longo de toda sua vida.

O segundo acontecimento foi a consolidação do movimento nacional-socialista na Alemanha, bem como o alastramento do domínio totalitário pela Europa.

Dentre as diversas contribuições de Hannah Arendt ao pensamento político e filosófico contemporâneo, certamente se destaca a análise do fenômeno totalitário - e é sobre tal acontecimento que o texto presente se propõe a analisar. O tema é abordado na obra Origens do Totalitarismo (1951), onde a escritora procura compreender como foi possível ocorrer o fenômeno totalitário, e quais os elementos que contribuíram para o seu surgimento.

No pensamento arendtiano, o fenômeno totalitário foi um evento de ruptura dos critérios políticos e morais tradicionais, demonstrando a própria deterioração da tradição do pensamento político. Segundo Arendt, esta era uma forma de dominação "sem precedentes" na história ocidental. Logo, a inédita insurgência compelia extrema dificuldade à sua compreensão, tendo em vista sua complexa conexão e, em diversos momentos, seus paradoxos estruturais (DUARTE, 2000, p.25).

A dominação totalitária como um fato estabelecido, que, em seu ineditismo, não pode ser compreendida mediante as categorias usuais do pensamento político, e cujos "crimes" não podem ser julgados por padrões morais tradicionais ou punidos dentro do quadro de referência legal de nossa civilização, quebrou a continuidade da História Ocidental. A ruptura em nossa tradição é agora um fato acabado. Não é o resultado da escolha deliberada de ninguém, nem sujeita a decisão ulterior (ARENDT, 1968, p.54).

\footnotetext{
${ }^{8}$ Sobre a influência destes dois pensadores vide LAFER, Celso. Hannah Arendt - Pensamento, Persuasão e Poder, p.23-24. E para mais detalhes sobre a influência de Heidegger: $O$ ser da Política e a política do ser: o confronto entre Hannah Arendt e Martin Heidegger em Ser e Tempo. Tese de doutoramento de Newton Pereira defendida em 2008 pela Universidade de São Paulo - USP. Disponível em $<$ http://www.teses.usp.br/teses/disponiveis/8/8133/tde-25112009-084807/pt-br.php $>$ Acesso em 15.05.2018.
} 
Segundo Arendt, foram os pensadores Heidegger e Benjamin que melhor compreenderam o "caráter irreparável da ruptura da tradição". Por meio de certos aspectos de tais pensadores, Arendt, além de redescobrir a origem esquecida da política na Antiguidade, estabeleceu uma radical reconsideração do significado da temporalidade histórica. Sendo assim, compreendeu que o passado apenas poderia ser renovado por meio do diálogo com a tradição, tendo em vista as reivindicações do presente e os contornos inacabados do futuro (DUARTE, 2000, p.26).

\title{
Conforme observou Duarte:
}

A grandeza e a originalidade do pensamento arendtiano residem em sua capacidade de pensar e reinventar a política ao repensar a tradição filosófica ocidental, definindo os pontos de tensão e intersecção entre política e filosofia. Seu pensamento nuançado opera segundo as regras de composição do claro-escuro, traçando um quadro matizado do presente no qual o rigor da compreensão crítica, e mesmo trágica, dos tempos sombrios complementa-se com o vislumbre dos pequenos clarões de esperança que ainda brilham num instante presente, sinais da promessa do passado para um futuro sempre aberto (DUARTE, 2000, p.30).

Em Origens do Totalitarismo, Arendt se tornou conhecida internacionalmente por suas análises ímpares e provocativas, o que lhe garantiu um lugar entre os pensadores mais profícuos e instigantes do século XX. Entretanto, por vezes, justamente a originalidade de seu pensamento dificulta sua compreensão. Em resposta a uma das críticas, Arendt relata que poderia explicitar melhor o método utilizado na referida obra:

\begin{abstract}
A crítica [...] levanta, de um lado, certas questões metodológicas muito gerais e, de outro, implicações fillosóficas gerais. Ambas, evidentemente, estão relacionadas; mas se de um lado sinto que, dentro das inevitáveis limitações de um estudo crítico e uma análise política, me fiz clara o suficiente sobre certas perplexidades gerais que surgiram com o pleno desenvolvimento do totalitarismo, por outro lado sei que deixei de explicar o método particular que empreguei, e de expor uma abordagem bastante incomum - não das diferentes questões históricas e políticas, em que uma explicação ou uma justificativa serviria apenas para distrair - do campo todo das ciências históricas e políticas como tais. Uma das dificuldades do livro é que ele não pertence a nenhuma escola, e não usa quase nenhuma ferramenta oficialmente reconhecida ou oficialmente controvertida (ARENDT, 2008, p.418).
\end{abstract}

Ao analisar o totalitarismo, Arendt apresenta uma exposição dos elementos que se cristalizaram no fenômeno: o antissemitismo e o imperialismo. Além do mais, tal exposição é acompanhada de uma análise da estrutura elementar da dominação e dos movimentos totalitários.

Sobre o antissemitismo, a pensadora relatou a conversão do preconceito social esparso sobre os judeus em uma política legalizada de discriminação. Assim, o antissemitismo passou 
da ordem particular para a figura do judeu, ou seja, a perseguição e discriminação passaram do âmbito de atitudes pessoais para o povo em geral.

Os acontecimentos políticos do século XX atiraram o povo judeu no centro do turbilhão de eventos; a questão judaica e o antissemitismo, fenômenos relativamente sem importância em termos de política mundial, transformaram-se em agente catalisador, inicialmente, da ascensão do movimento nazista e do estabelecimento da estrutura organizacional do Terceiro Reich, no qual todo cidadão tinha de provar que não era judeu ou descendente de judeus; e, em seguida, de uma guerra mundial de ferocidade nunca vista, que culminou, finalmente, com o surgimento do genocídio, crime até então desconhecido em meio à civilização ocidental (ARENDT, 1989, p.20).

Associadamente à perseguição dos judeus, incorpora-se o imperialismo com seu espírito expansionista do final do século XIX, suscitando questões tais como a decadência do estadonação, bem como de suas instituições; o anseio de conquistas de territórios em âmbito global; o racismo como argumento biológico para dominação, e a utilização da burocracia como meio de dominação política dos povos conquistados. Tais fatores cooperaram para o sentimento crescente de "superfluidade" dos seres humanos (DUARTE, 2000, p.33).

[...] a desintegração do Estado nacional, que continha quase todos os ingredientes necessários para gerar o subsequente surgimento dos movimentos e governos totalitários. Antes da era imperialista não existia o fenômeno de política mundial, e sem ele a pretensão totalitária de governo global não teria sentido. Durante esse período, contudo, o sistema de Estados nacionais revelou-se incapaz de elaborar novas normas para o tratamento de assuntos estrangeiros que se haviam tornado assuntos globais e de impor a sua pax romana ao resto do mundo. Sua estreiteza ideológica e miopia política conduziram ao desastre do totalitarismo, cujos horrores sem precedentes anularam a gravidade dos eventos ominosos e a mentalidade ainda mais ominosa do período precedente (ARENDT, 1989, p.151).

Arendt, em suas análises, pontua claramente que o fenômeno totalitário não é fruto específico do país alemão - como se pudesse ocorrer apenas naquele país ou estivesse destinado a ocorrer ali - mas que poderia acontecer em qualquer outro lugar ${ }^{9}$. O totalitarismo não é a ruptura das tradições alemãs somente; na realidade, é a ruptura das tradições europeias, mas devido ao panorama sócio-histórico sucedeu de ocorrer nas terras alemãs.

É verdade que a situação na Alemanha se prestava mais facilmente à ruptura do que em qualquer outro lugar. Tudo está relacionado com o desenvolvimento tardio da Alemanha como nação, com os infortúnios de sua história política e com a falta de qualquer tipo de experiência democrática. E está ainda mais relacionado com o fato de que a situação de inflação e desemprego no pós-guerra envolveu mais gente e afetou mais profundamente a Alemanha do que qualquer outro lugar. No entanto, mesmo que fosse mais fácil romper as tradições e os padrões europeus na Alemanha, permanece o fato de que tiveram de ser rompidos, de modo que o que gerou o nazismo

\footnotetext{
${ }^{9} \mathrm{O}$ totalitarismo foi concebido como um acontecimento fruto do mundo moderno e justamente por isso que Arendt pode admitir o fenômeno do stalinismo como uma vertente de sua tese totalitária (CANOVAN, 1992, p.19-20).
} 
não foi nenhuma tradição alemã em si, e sim a violação de toda e qualquer tradição (ARENDT, 2008, p.139).

A sustentabilidade dos governos totalitários provém do apoio das massas ${ }^{10}$. Eles as organizaram politicamente em prol do domínio total. As massas constituem vasta multidão caracterizada pela ausência de interesse comum, diferentemente das classes sociais, que se articulam em torno de objetivos comuns. É justamente entre as massas que os governos totalitários recrutam seus membros. Tais indivíduos haviam sido abandonados pelos outros partidos ou nunca haviam participado da política. Sendo assim, esses elementos teriam motivos para hostilizar os demais partidos ou serem apáticos em relação à vida política. Exatamente em razão desta condição amorfa das massas é que o totalitarismo angariou adeptos tão facilmente, pois foram convencidos da coerência e superioridade do regime totalitário.

\begin{abstract}
As massas não se unem pela consciência de um interesse comum e falta-lhes aquela específica articulação de classes que se expressa em objetivos determinados, limitados e atingíveis. O termo massa só se aplica quando lidamos com pessoas que, simplesmente devido ao seu número, ou à sua indiferença, ou a uma mistura de ambos, não se podem integrar numa organização baseada no interesse comum, seja partido político, organização profissional ou sindicato de trabalhadores. Potencialmente, as massas existem em qualquer país e constituem a maioria das pessoas neutras politicamente indiferentes, que nunca se filiam a um partido e raramente exercem o poder de voto (ARENDT, 1989, p.361).
\end{abstract}

A propaganda foi fundamental para o convencimento das massas, incutindo no homemmassa a ideologia total. A propaganda totalitária vai além da demagogia política, pois não se basta com a proliferação da mentira, mas permuta a verdade pela mentira. "O que outrora havia sido mera opinião ideológica se converteu no conteúdo vivo da realidade" (ARENDT, 2008, p.370), ou seja, a ficção torna-se realidade. O sucesso das ideologias totalitárias, no seio das massas, deve ser compreendido como mais um fruto da atomização social, bem como do colapso do tecido social:

O preparo triunfa quando as pessoas perdem o contato com os seus semelhantes e com a realidade que as rodeia; pois, juntamente comesses contatos, os homens perdem a capacidade de sentir e de pensar. O súdito ideal do governo totalitário não é o nazista convicto nem o comunista convicto, mas aquele para quem já não existe a diferença entre o fato e a ficção (isto é, a realidade da experiência) e a diferença entre o verdadeiro e o falso (isto é, os critérios do pensamento) (ARENDT, 1989, p.526).

\footnotetext{
${ }^{10}$ Apesar das massas constituírem a categoria central do fenômeno totalitário, esta não era o único elemento. $\mathrm{O}$ terreno social que fecundou o regime total também era composto pela ralé, elite e burguesia.
} 
Chama a atenção de Arendt a falta de razoabilidade do domínio total, que construiu fábricas para a produção de cadáveres sem nem ao menos levar em consideração sua utilidade econômica, haja vista que as deportações foram dispendiosas para o esforço de guerra. $\mathrm{O}$ antiutilitarismo de diversas instituições nazistas e soviéticas é peculiar a elas, não sendo encontrado em outras formas de governo, ditaduras e tiranias. Enquanto estas últimas desejam fins políticos, econômicos ou religiosos bem delimitados territorialmente, o totalitarismo não enxerga fronteiras, pois visa ao domínio total da população terrestre (DUARTE, 2000, p.63).

O terror é um dos elementos imprescindíveis do fenômeno totalitário e por meio dele o mundo deve se tornar um reflexo das premissas ideológicas totalitárias. Assim, faz-se necessário dominar o indivíduo até que ele perca sua espontaneidade e imprevisibilidade, exterminando qualquer espaço vital de liberdade que possa existir entre os homens, ou seja, a liberdade humana deve ser extirpada pela raiz. Aniquilar a liberdade humana consiste na eliminação da capacidade de o indivíduo iniciar algo novo. Portanto, é justamente pelo terror que o totalitarismo domina o homem em sua magnitude, aniquilando sua individualidade para que não haja a mínima atitude libertadora, e nem mesmo o mínimo intento mental de outra realidade que não a totalitária:

\begin{abstract}
Morta a individualidade, nada resta senão horríveis marionetes com rostos de homem, todas com o mesmo comportamento do cão de Pavlov, todas reagindo com perfeita previsibilidade mesmo quando marcham para a morte. Esse é o verdadeiro triunfo do sistema: $\mathrm{O}$ triunfo da SS exige que a vítima torturada se deixe levar à forca sem protestos, que renuncie e se entregue ao ponto de deixar de afirmar a sua identidade. Não é gratuitamente nem por mero sadismo que os homens da SS desejam a sua submissão. Sabem que o sistema que consegue destruir a vítima antes que ela suba ao patíbulo (...) é, sem dúvida, o melhor para manter um povo inteiro na escravidão, na submissão. Nada é mais terrível que essas procissões de seres humanos que vão para a morte como fantoches (ARENDT, 1989, p.506).
\end{abstract}

O domínio total alcança sua perfeição nos campos de concentração. Eles constituem a mais importante instituição dos regimes totalitários, não somente devido à ultrajante dominação sem precedentes. Conforme Arendt, "o domínio total, que procura sistematizar a infinita pluralidade e diferenciação dos seres humanos como se toda a humanidade fosse apenas um indivíduo, só é possível quando toda e qualquer pessoa seja reduzida à mesma identidade de reações" (ARENDT, 1989, p. 506).

A verdadeira finalidade dos campos de concentração consiste "de não servirem pra coisa alguma, senão para a destruição da liberdade; e a de não gerarem produto final algum, a não ser a pilha de cadáveres" (DUARTE, 2000, p.68). As mais execráveis condições sociais anteriores, como a escravidão, não podem se comparar ao absurdo vivido pelos detentos dos campos de 
concentração. Os escravos ao menos possuíam um preço e função social, já os detentos eram como "cadáveres vivos". "O prisioneiro dos campos de concentração deixa de ser alguém com vida pregressa e, no limite, é como se ele nunca houvesse existido" (DUARTE, 2000, p.69).

Arendt defendeu este ponto de vista:

O verdadeiro horror dos campos de concentração e de extermínio reside no fato de que os internos, mesmo que consigam manterem-se vivos, estão mais isolados do mundo dos vivos do que se tivessem morrido, porque o horror compele ao esquecimento. No mundo concentracionário mata-se um homem tão impessoalmente como se mata um mosquito. Uma pessoa pode morrer em decorrência de tortura ou de fome sistemática, ou porque o campo está superpovoado e há necessidade de liquidar o material humano supérfluo. Inversamente, pode ocorrer que, devido a uma falta de novas remessas humanas, surja o perigo de que os campos se esvaziem, e seja dada a ordem de reduzir o índice de mortalidade a qualquer preço (ARENDT, 1989, p.493).

Portanto, conforme descrito, o totalitarismo é um conceito muito bem desenvolvido no pensamento arendtiano. Para a autora, os métodos do domínio total não são apenas mais extremados; na realidade, são diferentes de outras formas de opressão políticas experimentadas, como o despotismo, a tirania e a ditadura (ARENDT, 1989, p.512). O totalitarismo, alicerçado na organização burocrática de massas, promoveu uma nova forma de governo firmado no emprego do terror e da ideologia.

\section{Considerações finais}

Não é exagero dizer que o mundo jamais foi o mesmo após as atrocidades do fenômeno totalitário. Tanto é verdade que até mesmo em relações sociais básicas, como debates na internet, Adolf Hitler é invocado como argumento, ou seja, comparam a pessoa ou pensamento que se quer desconstruir ao líder alemão. Justamente por isso que o advogado e escritor Mike Godwin desenvolveu a lei de Godwin na qual afirma: "quando uma discussão online se prolonga, a probabilidade de surgir uma comparação envolvendo Adolf Hitler ou o nazismo aproxima-se de 100\%". Tais comparações chegam a ser absurdas até mesmo para o senso comum. Por exemplo, houve o caso de quem utilizasse o nazismo como argumento contra o vegetarianismo e subsídios à indústria, pois alegaram que tais práticas são condenáveis simplesmente porque o líder alemão era adepto a elas ${ }^{11}$. Além do mais, uma rápida pesquisa nos meios de comunicação demonstrará dezenas de atribuições totalitárias nos dias atuais.

11 Disponível em $<$ https://www.cartacapital.com.br/internacional/trump-desmoraliza-a-lei-de-godwin3166.html> Acesso em 19/08/2018. 
Justamente devido a tal banalização, resgatou-se o conceito do fenômeno totalitário, conceituação na qual Hannah Arendt se ateve à intrigante ruptura na tradição do ocidente causada pelo fenômeno totalitário. Compará-lo a algum fato do passado não é possível, pois se trata de algo original. Logo, a partir do novo evento, Arendt repensou a política e a tradição do pensamento político, pois se tornaram ineficazes não somente todos os conceitos políticos e definições, mas também todas as categorias de pensamento e padrões de julgamento.

Assim, o fenômeno totalitário, por meio da destruição do terreno da política, fazia do terror uma forma central de relacionamento entre Estado e cidadãos. Logo, os governos totalitários procuravam controlar todos os aspectos do homem com o intuito da dominação total dos seres humanos pelo terror.

Conclui-se que, dentre as diversas contribuições de Hannah Arendt ao pensamento político e filosófico contemporâneo, certamente se destaca a análise do fenômeno totalitário. Estes estudos contribuem como ferramenta de análise frente aos possíveis domínios totais ou qualquer faísca de ressurgimento desta abominável forma de governo.

Por fim, como foi dito na introdução, a proposta do texto não é a análise ou classificação de atitudes e líderes como totalitários ou não. Isto poderá ser feito em um segundo momento. Aqui se preocupou em resgatar o conceito arendtiano de totalitarismo, pois o termo tem sido utilizado largamente no senso comum. Portanto, o artigo presente se faz necessário justamente para evitar tais equívocos e distorções, ou seja, para que se esquadrinhe assertivamente tal conceito arendtiano a indivíduos contemporâneos.

\section{Referências bibliográficas}

ADEODATO, João Maurício Leitão. O problema da legitimidade: no rastro do pensamento de Hannah Arendt. Rio de Janeiro: Forense Universitária, 1989.

ARENDT, Hannah. Compreender: formação, exílio e totalitarismo (ensaios) 1930-54. Tradução Denise Bottman; organização, introdução e notas Jerome Kohn. São Paulo: Companhia das Letras; Belo Horizonte: Editora UFMG, 2008.

Perspectiva, 1968.

. Entre o passado e o futuro. Tradução Mauro W. Barbosa. São Paulo:

. The Jew as Pariah - Jewish identity and politics in the modern age. Edited and with an introduction by Ron Feldman. New York, Grove Press, 1978.

Companhia das Letras, 1989.

Origens do totalitarismo. Tradução Roberto Raposo. São Paulo: 
CANOVAN, Margaret. The political thought of Hannah Arendt. New York-London, Ed. Harvert-HJB, 1974.

DUARTE, André. O pensamento à sombra da ruptura: política e filosofia em Hannah Arendt. São Paulo: Paz e Terra, 2000.

LAFER, Celso. Hannah Arendt - Pensamento, Persuasão e Poder. Rio de Janeiro, Ed. Paz e Terra, 1979.

- A reconstrução dos direitos humanos: um diálogo com o pensamento de Hannah Arendt. São Paulo: Companhia das Letras, 1988.

PEREIRA, Newton Gomes. O ser da Política e a política do ser: o confronto entre Hannah Arendt e Martin Heidegger em Ser e Tempo. Tese de doutorado em filosofia. São Paulo: USP, 2008. Disponível em <http://www.teses.usp.br/teses/disponiveis/8/8133/tde-25112009084807/pt-br.php $>$ Acesso em 15.05.2018. 